mean percentage increase in PEF was $56.5 \%$ (95\% CI $39 \cdot 5$ to $73 \cdot 5)$. Sixty eight patients (79\%) had a $>10 \%$ increase in PEF and in 14 $(16 \%)$ there was no change. In four $(5 \%)$ there was a $>10 \%$ fall in PEF but all made an uneventful recovery after admission to hospital. Subjective assessments by ambulance personnel (131 treatments) showed $79 \%$ improved, $18 \%$ unchanged, and $3 \%$ worse. No unwanted side effects from nebuliser therapy were recorded. All patients were discharged uneventfully from hospital.

\section{Discussion}

Most patients with acute severe asthma given nebulised $\beta$ agonist treatment in an ambulance en route to hospital gain a significant improvement in airflow obstruction as measured by PEF. This supports subjective data on the response of patients obtained previously from ambulance personnel. ${ }^{245}$ Our protocol allowed crews to treat patients with asthma under the age of 40 who had not been seen by a medical practitioner. The age limit was set in an attempt to avoid the administration of high flow oxygen to patients with chronic bronchitis and emphysema who may have abnormal ventilatory responses. No adverse effects were seen and it is possible that delays in delivering an effective treatment were avoided. Giving a nebulised $\beta$ agonist in an ambulance has advantages over using an air driven nebuliser in the patients' homes before the journey to hospital. Transfer to hospital is not delayed which may be vital in rural areas where long distances may need to be travelled to the nearest hospital. In addition, the drug can be nebulised in oxygen which reduces the risk of increasing hypoxaemia which may occur in patients with severe asthma when bronchodilators are nebulised in air.

Our data show that salbutamol nebulised in high flow oxygen is an effective and safe treatment for acute asthma when administered by ambulance personnel. We would encourage all ambulances to be equipped with this simple, cheap and possibly life saving facility.

1 British Thoracic Society, Research Unit of the Royal College of Physicians of London, King's Fund Centre, National Asthma Campaign. Guidelines for management of asthma in adults: II - Acute asthma. BMF 1990;301:797-800.

2 Wathen CG, Crompton GK, Carrington D, Hollingworth J. Treatment of acute asthma in the ambulance. Br $\mathcal{F} \mathrm{Gen}$ Pract 1990;40:388.

3 Crompton GK, Grant IWB. Edinburgh emergency asthma admission service. $B M \mathcal{F} 1975 ; 4: 680-2$.

4 Hill LS. The use of nebulised salbutamol by ambulance personnel. Thorax 1987;42:719.

5 Murphy S. Emergency nebulised salbutamol and the ambulance service. Scott Med f 1987;32:93.

\title{
District nebuliser compressor service: reliability and costs
}

\author{
Mary E Dodd, Simon P Hanley, Susan C Johnson, A Kevin Webb
}

\begin{abstract}
Background - There is little information on the costs of maintaining a district nebuliser compressor service. This retrospective study examines the issue, reliability, and maintenance costs of electrical compressors to assist the prediction of future costs, taking into account recent safety legislation.

Methods - Records of issue, repair, and replacement for the period 1982-91 were reviewed. The current policy of repairing and replacing as necessary, and three other theoretical costings, were considered.

Results - The number of compressors being issued is increasing. Repaired compressors are less reliable and frequency of repair is a function of compressor age. The current policy is the most cost effective.

Conclusions - To repair and replace nebuliser compressors as necessary is the most economical policy under the present terms offered by the manufacturers, but changes in safety legislation will affect the provision of such services. (Thorax 1995;50:82-84)
\end{abstract}

Keywords: outpatient, nebuliser, cost.
North Manchester Health Authority (NMHA) has experienced an increasing demand for the provision of electrical compressors used to power nebulisers for the delivery of drugs in the treatment of lung disease. It is the statutory responsibility of the Health Authority to maintain equipment provided as part of NHS treatment. ${ }^{1}$ Recommendations for servicing have been issued by the British Thoracic Society ${ }^{2}$ and general guidelines on electrical safety by the Department of Health. ${ }^{3}$ However, there are no data available on the reliability of compressors, and the merits of "regular service" compared with "as necessary maintenance" (repair including service at time of repair) on which to base recommendations.

Our policy for a 10 year period has been to repair and replace as necessary. Compressors are "replaced as necessary" if considered to be beyond economical repair by the manufacturer or agent's definition (usually parts and labour costs in excess of $£ 25$ ).

The data presented in this study are an analysis of our compressor service, examining aspects of development, repair, and replacement, in an attempt to develop a model which may be applied to a population of compressors to allow for prediction of future costs. 


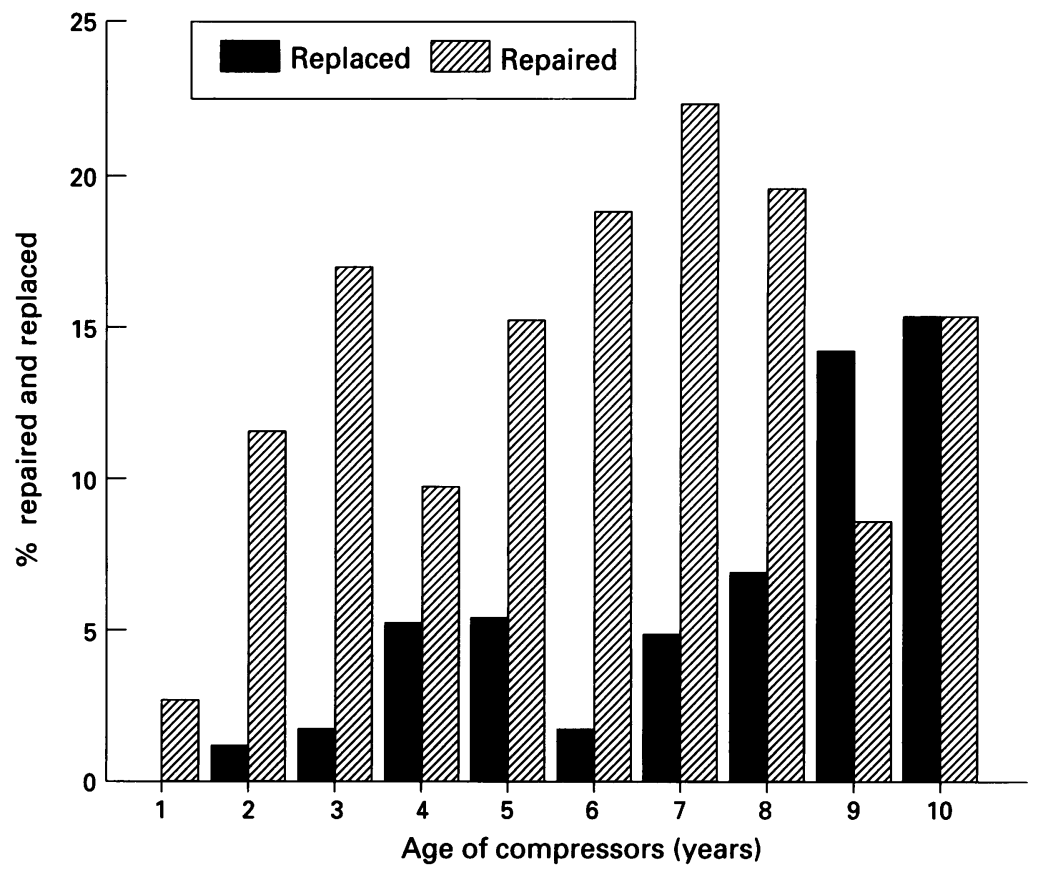

Figure 1 Number of compressors repaired and replaced per year in each age band expressed as a percentage of the total number of compressors of that age.

\begin{abstract}
Methods
Data on compressors from three different manufacturers (Bard, Sunderland; Charles Austen, Weybridge; and Medix, Lutterworth) were analysed with regard to purchase, issue and reissue, and repair and replacement for the years 1982-91 inclusive. From this information details of the annual rate of issue, estimates of compressor reliability, and costings were derived.
\end{abstract}

ISSUE OF COMPRESSORS

The total number of new patients per year issued with a compressor (inclusive of re-used compressors) was identified.

\section{RELIABILITY OF COMPRESSORS}

Repair and replacement: effect of compressor age The number of compressors repaired and replaced per year for each age band of compressor was expressed as a percentage of the total number of compressors having been within that age group. The percentage of compressors remaining functional by year of purchase was also calculated.

\section{Reliability of repair}

The mean and range of the times from purchase to first repair, first to second, and second to third repair were calculated. No compressor was repaired a fourth time. The reliability of new machines was compared with that of repaired machines by determining the cumulative total of repairs per year for the first three years following purchase (inclusive of compressors considered beyond economical repair), expressed as a percentage of the total number of compressors purchased up to 1989 inclusive. This procedure was repeated for the number of repairs per year for the first three years after a first repair, and expressed as a percentage of the total number of compressors repaired once up to 1989 inclusive.

To determine the effect of age of compressor on repair, the relationship between the age of compressor at first repair (up to seven years) and the percentage repaired over the next three years was examined.

\section{TOTAL COSTS FOR THE 10 YEAR PERIOD}

(EXCLUDING INITIAL PURCHASE)

The costs of providing the service were based on assumptions of present day costs - that is, average new compressor $£ 100$ (for replacement), average repair $£ 20$, and average service charge $£ 15$ (external contractors). The total costs of the departmental repair and replace as necessary policy were compared with the costs of three other policies: (a) repair once only and replace, (b) replace and never repair, and (c) regular annual service (assuming repairs never required).

In addition to our policy of repair and replace as necessary, our practice consists of three monthly replacement of filters and an annual pressure and flow check, but no routine internal inspection. A 24 hour service is provided (including home visits) for the breakdown of compressors. A broken compressor is exchanged for a functional compressor from a "stock pool". Following repair the machine is returned to stock and not to the original patient.

\section{Results}

ISSUE OF COMPRESSORS

Two hundred and eighty compressors were purchased, 47 of which were bought as replacements (Bard, $\mathrm{n}=157,1982-7$; Charles Austen, $\mathrm{n}=22$, 1988; Medix, $\mathrm{n}=101$, 1989 91 ). A total of 447 patients were issued with a compressor at a rate of $20-40$ per year between 


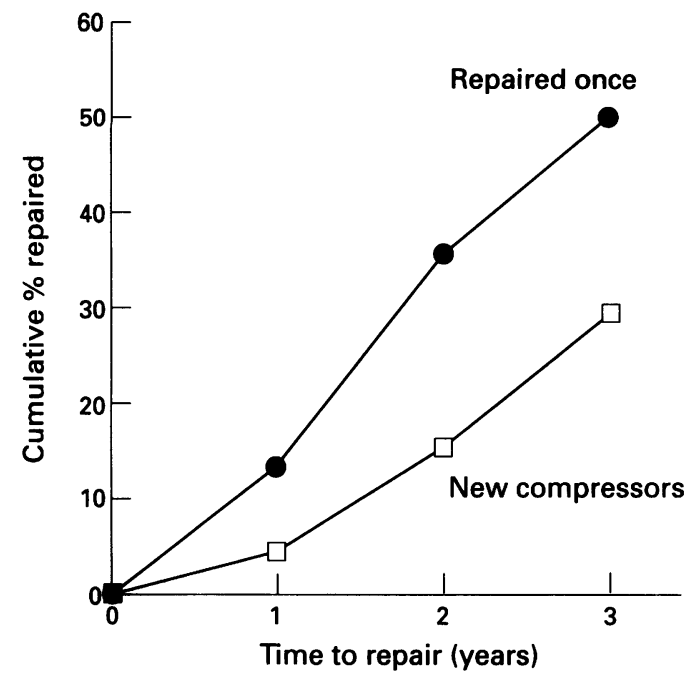

Figure 2 Comparison of the rates of repair over a three year period for new compressors $(n=215)$ and compressors that have been repaired once $(n=76)$.

1982 and 1987, which had risen to 104 per year by 1991 .

\section{RELIABILITY OF COMPRESSORS}

Repair and replacement: effect of compressor age With increasing age, more compressors required replacement but the annual rate of repair was not clearly linked (fig 1). More than $95 \%$ of compressors purchased between 1988 and 1991 inclusive were still functional, and over $50 \%(22 / 42)$ of those purchased in 1982 remained in service.

\section{Reliability of repair}

One hundred and thirty six compressors required one or more repairs. The mean (range) time from purchase to first repair $(n=136)$, from first to second repair $(n=62)$, and from second to third repair $(n=20)$ was $3.6(0.5-$ $9 \cdot 8), 2 \cdot 2(0 \cdot 16-5 \cdot 16)$, and $1.5(0 \cdot 33-3 \cdot 58)$ years respectively, suggesting that repaired compressors were less reliable.

Two hundred and fifteen compressors were purchased up to 1989 inclusive (only 36/101 Medix) and 76 had a first repair up to 1989 (no Medix compressors included). The reliability of new compressors compared with those repaired once only over a three year period is shown in fig 2 which shows that repaired compressors are less reliable than new ones. There was a positive correlation between the age of com- pressor at first repair and the percentage repaired over the following three years $(r=0.81$, $\mathrm{p}<0.05$ ), indicating that further repair is a function of age.

TOTAL COSTS FOR THE 10 YEAR PERIOD (EXCLUDING INITIAL PURCHASE)

The calculated cost for the 10 year period of our policy to repair and replace as necessary was $£ 8120$ compared with the theoretical alternative policies of (a) repair once only and replace ( $£ 10200)$, (b) replace and never repair (£13600), and (c) regular annual service assuming no repair and replacements required (£17 625).

\section{Discussion}

This study confirms the finding of Hosker $e t$ $a l^{4}$ that the issue of electrical compressors is increasing. Repaired compressors are less reliable than new ones, but to repair and replace as necessary proved to be the most economical option. How frequently, and to what extent routine servicing should be carried out is not absolute, and, as shown in this study, over $70 \%$ of compressors did not require repair at three years after purchase (fig 2). However, general guidelines issued by the Department of Health/ BTS regarding the regular servicing and safety checking of all electrical equipment suggest a frequency of every 3-6 months. ${ }^{23}$

Our figures show that comprehensive annual servicing alone would double the expenditure of our policy. The Department of Health recommendations of three monthly servicing, if undertaken as full preventative maintenance with internal inspection of the compressors, would clearly be extremely costly.

As a result of recent safety legislation we plan to introduce routine basic servicing, to be undertaken by the physiotherapy staff after suitable training, consisting of external inspection for damage and electrical safety testing on a yearly cycle. ${ }^{5}$

1 NHS Management Executive. Provision of equipment by the NHS. 1993.

2 British Thoracic Society, Research Unit of the Royal College of Physicians of London, King's Fund Centre, National Asthma Campaign. Guidelines for management of asthma

3 Department of Health. Safety of electrical medical and laboratory equipment. Safety Action Bulletin No 74 SAB (91)57,1991.

4 Hosker HSR, Teale C, Muers MF, Greenstone MA. Provision of home nebulisers in Yorkshire. Thorax 1992;47:863P

5 Allison R. Putting electrical safety in perspective. Physiotherapy 1993;79:471. 